\title{
The Development of Medical Education Under 5G Technology
}

\author{
Xiaolei Yang ${ }^{1}$, Guangming Lan $^{1 *}$ \\ ${ }^{1}$ School of Continuing Education, Kunming medical University, Kunming, , China \\ *Corresponding Author.
}

\begin{abstract}
:
This paper studies the development of medical education under $5 \mathrm{~g}$ technology, and explores a new mixed teaching mode under the background of medical reform based on $5 \mathrm{~g}$ network technology and competency. This paper supports students' real-time streaming media and realtime online interaction in the form of multipoint and multi terminal, and carries out a series of medical integration education courses based on $5 \mathrm{G}$ network. In addition, formative assessment is conducted after each class. A comprehensive evaluation system is formed through feedback reflection guidance and summative evaluation in the last class. This can help students improve their core competitiveness. The results show that $5 \mathrm{G}$ network provides experienced data rate and meets the bandwidth requirements of downlink and uplink throughput in the course. The formative assessment and feedback cycle supported by $5 \mathrm{G}$ network can be used on the platform to predict medical students' learning habits and scores more quickly and accurately, which is helpful to improve the quality of education and teaching. The realization of medical education through $5 \mathrm{G}$ network technology is a new exploration of teaching mode. It can not only improve the learning initiative and enthusiasm of medical students, but also cultivate and improve the core competence of medical students.
\end{abstract}

Keywords: $5 G$ technology, Medical education, Competency, Medical reform.

\section{INTRODUCTION}

The improvement of economic income makes people pay more attention to the quality of life, and medical and health services have always been the focus of people's attention. Combined with the background of the current social and economic reform, it can be found that the demand for high-quality medical and health services in social life is increasing [1]. This practical demand has a very important impact on higher medical education. Therefore, the cultivation of medical talents has become an issue that must be paid attention to in modern society [2-4]. The purpose of medical education is to meet the high-quality needs of people's 
Article History: Received: 28 October 2021 Revised: 05 December 2021 Accepted: 10 January 2022 Publication: 28 February 2022

medical services, so there is a great difference between the talents exported by medical education and the talents exported by mass education and vocational education [5]. This special law also shows that the quality of medical education is closely related to people's life, so it must be strictly managed and supervised.

While exploring the quality of higher medical education, this paper introduces the concept of quality management and the method of Balanced Scorecard, hoping to provide effective suggestions for improving the quality of medical teaching and medical education and teaching reform, so that medical colleges and universities can actively establish a teaching quality assurance system [6-7]. Taking on the important task of exporting high-quality medical talents for the society, and solving the problem faced by Chinese colleges and universities that only expand the scale and can not keep up with the quality of education [8].

\section{CURRENT SITUATION AND PROBLEMS OF MEDICAL EDUCATION QUALITY IN COLLEGES AND UNIVERSITIES}

1.Current situation of medical education quality in Colleges and Universities

Medical research and implementation are mainly aimed at people who have physical and mental diseases and need help, which makes the content of medical education special and highlights the importance of medical profession.

(1) The curriculum of medical education in China. Medical education in Colleges and universities in China is directly admitted to medical colleges after graduating from high school. After five years of medical education, we have obtained a bachelor's degree; On this basis, he will receive re education for $2 \sim 3$ years, complete master's education and obtain a master's degree. On the basis of master's degree, carry out doctoral education for $3 \sim 4$ years. At present, dozens of colleges and universities in China have begun to train seven-year postgraduate medical master students, but the undergraduate teaching mode still occupies a dominant position.

(2) Present situation of practice teaching. With the improvement of people's living standards, people's awareness of self-care has been strengthened and doctor-patient interaction has been increased. Due to the imperfect medical system in China and the influence of some external media, the doctor-patient relationship is tense and doctor-patient disputes often occur. The existence and intensification of these contradictions greatly reduce the opportunities for students' clinical practice and the direct communication and interaction with patients. Even if they participate in clinical practice, some patients often refuse to accept their consultation or examination due to lack of trust in interns. There is no or lack of practice opportunities, which seriously affects the ability training of interns.

(3) Basic experience in the construction of medical education quality management system. The construction of medical teaching quality management system is divided into external 
Article History: Received: 28 October 2021 Revised: 05 December 2021 Accepted: 10 January 2022 Publication: 28 February 2022

quality management system and internal quality management system. The establishment of external quality system further guides the construction and improvement of internal education quality system. The construction of teaching quality system needs to fully refer to the internal and external environment. Usually, medical colleges refer to the internal environmental problems of teaching when building the medical education quality system. However, we do not pay enough attention to the external environment, which also leads to the established quality assurance system still staying in the internal water, moon and fog. Therefore, when constructing the teaching quality assurance system, we should not only pay attention to the internal environment, but also make effective exploration in combination with the external policy, market and other environment.

2.Analysis on the problems and causes of teaching quality

Problems in the quality of medical education in Colleges and Universities:

(1) Students. Through the questionnaire, it is found that in terms of students' curriculum, each school also offers different medical related courses, including doctor-patient communication, basic medical courses, community health service management, prevention and health care and professional courses. These courses can enable medical students to have a deeper understanding of the construction of China's medical system, which is of great help to cultivate the working ability of medical students. However, many undergraduate students in medical education colleges generally have some bad learning habits, and their learning enthusiasm is not high and their learning purpose is not clear. There is a prominent phenomenon of "mixed diploma".

(2) School. China has carried out a long-term medical education reform for medical problems, but in the process of specific implementation, the particularity of medical education makes the medical education reform very difficult. There are many problems in the quality control of medical education in Colleges and universities. These problems also directly determine that there is a certain gap between the personnel output by colleges and universities for the society and the actual needs of the society.

Analysis on the causes of problems in teaching quality:

The evaluation mechanism is an important link to test the teaching quality. From the survey results alone, the teaching quality standard of colleges and universities is still in the exploration stage, and its maturity and rationality are still relatively lacking. Only $20 \%$ of colleges and universities believe that the current teaching evaluation mechanism is "more reasonable".

At present, 42 colleges and universities (84\%) have established a medical education and teaching quality management system, but they actually adopt the method of target management. The so-called colleges and universities that have announced the adoption of total quality management are just "virtual adoption", but they have not really implemented it. This approach enables colleges and universities to get some benefits or keep their vested interests without having to pay a lot of expenses for innovation. Many colleges and universities give up total 
Article History: Received: 28 October 2021 Revised: 05 December 2021 Accepted: 10 January 2022 Publication: 28 February 2022

quality management soon after virtual adoption.

The current medical education evaluation system has a single index, which can not play a good guiding role in the talent output of medical education. Only by changing the management mode of medical education from the aspects of teaching evaluation content, information feedback rectification system, education and teaching reform and quality culture construction, and optimizing the quality assurance mechanism of medical education, can the quality of medical education be fundamentally improved. Balanced scorecard is not only a comprehensive evaluation system, but also an important reference for strategic planning in Colleges and universities. Therefore, the introduction of balanced scorecard based performance evaluation system can more comprehensively and objectively evaluate the quality of medical education. The strategic objectives determined by the Balanced Scorecard need corresponding education quality management. They work together to form a perfect university education quality management system and improve education quality.

\section{CONSTRUCTION OF MEDICAL EDUCATION QUALITY EVALUATION SYSTEM BASED ON BALANCED SCORECARD}

1.Implementation steps of Balanced Scorecard in higher medical education evaluation

Referring to the research results of the balanced scorecard, this paper combs the general paradigm of the application of the Balanced Scorecard in the internal quality assurance system of Higher Education:

First, clarify the nature of higher education non-profit organizations and determine the development strategy of the University. Higher education institutions are non-profit organizations. To introduce the balanced scorecard, we should first make it clear that the mission of colleges and universities is not to absorb interests, but to enable every student to apply what they have learned and export talents for the development of the country and society. Only in this way can the application of higher education quality assurance system and balanced scorecard be well combined.

Second, use the strategy map to effectively describe the strategy. The problems in the construction of teaching quality assurance system in Colleges and universities mainly lie in the fact that they have not effectively defined the strategic objectives. Although most schools have formulated development strategies according to their own development, in many cases, they do not implement the strategic objectives to the operation level, but only stay at the slogan level. The strategic map effectively checks the development plan of colleges and universities, so as to help colleges and universities clarify their strategic objectives and tasks.

Third, the decomposition of strategic objectives needs to be combined with the specific management mode of colleges and universities. The university is an organization with a longterm development strategy, so in the implementation of the overall strategic objectives, it is 
Article History: Received: 28 October 2021 Revised: 05 December 2021 Accepted: 10 January 2022 Publication: 28 February 2022

necessary to decompose the strategic objectives and combine the regulation and management strategies of the University. Then locate the strategic map according to the responsibilities of each functional department, and confirm the internal operation process by using the balanced scorecard.

Fourth, use effective communication to establish a quality assurance system based on the balanced scorecard. After the strategic objectives are determined, colleges and universities need to decompose layer by layer in combination with the responsibilities of various functional departments. In the specific decomposition process, they need to compare the indicators in combination with the Balanced Scorecard theory. It is worth noting that in the process of strategic decomposition, it is necessary to effectively communicate with various departments and effectively integrate the quality assurance system in full combination with the pursuit of the Department.

Fifth, repair the Balanced Scorecard and strategic map in combination with practical changes. The construction of quality assurance system is a complex system engineering. In the specific implementation process, we must realize that this is a long-term work. Therefore, in the specific implementation process, it is necessary to effectively repair the Balanced Scorecard and strategic map in combination with the development of practice, so as to make the construction of quality assurance system more suitable for the development of teaching practice.

2.Application of Balanced Scorecard in medical education quality evaluation system -Taking S University as an example

S University is a key comprehensive university directly under the Ministry of education with a long history, complete disciplines, strong academic strength and distinctive school running characteristics. It is one of the high-level universities under the national "211 Project" and "985 Project". It was selected as a "double first-class" University in 2017.

According to the medical development of s University, combined with the three levels of the balanced scorecard, the specific strategic objectives are effectively divided and organized.

As the representative of non-profit organizations, colleges and universities need to clarify the identity of customers, such as students, employers, government, social service units, etc., but students are the source of things. Only by truly solving the students' problems can we improve the teaching quality of higher education. Students need to work after graduation. Although the treatment provided by different employers is different, it also belongs to the scope of services required by the school. The government undertakes the heavy responsibility of allocating funds to the society, so colleges and universities need to be responsible to the government. Social service units are organizations that receive consultation from colleges and Universities Based on social units, and they also have close ties with colleges and universities. Through the observation of these dimensions, it can be found that medical education should clarify its own customer groups in specific services, and divide the strategic objectives according to different customer levels, as shown in Table 1. 
Article History: Received: 28 October 2021 Revised: 05 December 2021 Accepted: 10 January 2022 Publication: 28

TABLE I. S University medical education aims at serving customers

\begin{tabular}{|c|c|}
\hline SERVING & STRATEGIC TARGET \\
CUSTOMERS & PTUDENTS AND \\
EMPLOYERS & Provide high-quality teaching services and excellent professionals \\
\hline SOCIOLOGY & Provide innovative technology \\
\hline INVESTOR & Become an efficient professional education base \\
\hline
\end{tabular}

Internal process is a part that every organization must involve, and it can also reflect customer value. The key to the strategic success of a medical university is to obtain customer satisfaction. Therefore, it is necessary to subdivide the internal process, such as teaching process, administrative process, etc. the strategic objectives in the subdivision of the internal process of Medical University are shown in Table 2.

TABLE II. Strategic objectives of S University Medical Education for internal processes

\begin{tabular}{|c|c|}
\hline PROCESS CONTENT & STRATEGIC TARGET \\
\hline TEACHING & Improving the quality and hardware setting of teaching \\
activities
\end{tabular}

S University medical education is a knowledge intensive organization, so in the specific implementation process, we need to pay attention to our own learning and growth, so we need to make effective use of information capital, scientific research ability and human capital. However, these three levels have also laid a material and human foundation for the school's learning and growth, as shown in Table 3.

TABLE III. S the strategic goal of university medical education for organizational change

\begin{tabular}{|c|c|}
\hline CHANGE & STRATEGIC TARGET \\
\hline $\begin{array}{c}\text { INFORMATION } \\
\text { TECHNOLOGY }\end{array}$ & $\begin{array}{c}\text { Improve the software and hardware equipment of each port } \\
\text { shared by the information platform }\end{array}$ \\
\hline $\begin{array}{l}\text { SCIENTIFIC } \\
\text { RESEARCH }\end{array}$ & Scientific research achievements \\
\hline
\end{tabular}


Article History: Received: 28 October 2021 Revised: 05 December 2021 Accepted: 10 January 2022 Publication: 28 February 2022

\section{MANPOWER \\ Teacher motivation and training}

\section{GUARANTEE MEASURES OF EDUCATIONAL QUALITY MANAGEMENT IN COLLEGES AND UNIVERSITIES}

The construction of medical education and teaching quality management system is in the cultural atmosphere, so in the process of implementation, we should pay great attention to quality culture and strengthen the construction of quality leadership system, quality organization and quality system in each campus. Strengthen publicity, carry out quality management activities in strict accordance with the rules and regulations of the school, and form a consistent quality behavior culture and quality system culture of the whole school. Only by bringing quality culture into the scope of quality management system can we promote its complete development. Culture is presented in a subtle way, and the quality culture of colleges and universities is no exception. Therefore, only by building a good quality cultural atmosphere can we change the thoughts of teaching staff and make the teaching staff better serve students. Realize the transformation of school educational objectives and educational quality, and deepen the sense of responsibility and identity of staff and students in the process of cultural edification, so as to provide spiritual support for the construction of medical education and teaching quality management system.

In order to make "quality management" survive and develop well in the higher education system, from the organizational perspective, higher education needs to "establish a quality centered organizational structure, successfully integrate quality as a new variable into the organizational design and operation of the University, innovate the organizational structure and system of the University, and create a learning university." If colleges and universities can develop into "universities as quality organizations", it will be easy to carry out any kind of quality management activities. At the same time, in order to ensure that the indicators set for quality management are scientific and reasonable, we also need the guidance of the expert team, cultivate the professional team of quality management, and guide the orderly progress of education quality management.

In the process of quality data collection, we need to master multivariate statistical methods and the operation of various software required for index compilation. In addition to professional teams, we also need corresponding technical systems as support. For example, the collection of information data needs to be supported by a data collection platform. Data analysis and statistics; The calculation of index needs to be supported by corresponding statistical software and index compilation software; The release of evaluation conclusion and index needs to be supported by a certain release platform, so as to ensure the timeliness and openness of index release. At the same time, the school overall design quality management information system. The information work office should take the lead to integrate various information systems of the school, develop 
Article History: Received: 28 October 2021 Revised: 05 December 2021 Accepted: 10 January 2022 Publication: 28 February 2022

a mobile network platform of teaching evaluation system based on information technology such as wechat platform and mobile client, fully realize the sharing of school data and information, and release feedback in time. Carry out cooperation and constantly improve the information construction of supervision and evaluation of teaching.

\section{CONCLUSION}

China strongly advocates the establishment of an effective quality management system, constantly and steadily improve the quality of medical education in Colleges and universities, and provide information sources for educational decision-making. The quality management system of higher medical education based on the balanced scorecard can be used to study and develop the quality of medical education in Colleges and universities. At the same time, the strategy can be transformed into a specific action plan, and the emphasis on the decomposition of strategic objectives includes both the innovation of management concept and the improvement of management system. The significance of balance is not limited to stability, but to reward excellence and make up for deficiencies in continuous communication and feedback, so as to realize overall development and continuously inject vitality into the quality management of higher medical education. Using the Balanced Scorecard to establish a communication bridge to form the feedback mechanism in the school is conducive to the communication and management between various departments of the school and between teachers and students. At the same time, based on the balanced scorecard, strategic communication is not only the system and guarantee related to the communication and teaching evaluation between colleges and universities, but also the premise and guarantee to improve the competitiveness of colleges and universities.

\section{REFERENCES}

[1] Degroat, R. D. , Vis, M. , \& Bliss, W. G. . (2001). Experimental characterization of media noise based on equalized, synchronized drive data. IEEE Transactions on Magnetics, 37(2), 633-638.

[2] Xia, P. , \& Zhou, H. . (2017). A novel popular tourist attraction discovering approach based on geotagged social media big data. ISPRS International Journal of Geo-Information, 6(7), 216.

[3] Neville, M. C. , Keller, R., Seacat, J., Lutes, V., Neifert, M. , \& Casey, C. , et al. (1988). Studies in human lactation: milk volumes in lactating women during the onset of lactation and full lactation. American Journal of Clinical Nutrition, 48(6), 1375-1386.

[4] Wong, A. K. Y. , Ray, P. , Parameswaran, N. , \& Strassner, J. . (2006). Ontology mapping for the interoperability problem in network management. IEEE Journal on Selected Areas in Communications, 23(10), 2058-2068.

[5] Li, D. , Zhang, Y. , \& Li, C. . (2019). Mining public opinion on transportation systems based on social media data. Sustainability, 11. 
Article History: Received: 28 October 2021 Revised: 05 December 2021 Accepted: 10 January 2022 Publication: 28 February 2022

[6] Zhang, Y. X. , Feng, Y. X. , \& Yang, R. Q. . (2019). Network public opinion propagation model based on the influence of media and interpersonal communication. International Journal of Modern Physics B, 1950393.

[7] Feng, Z. . (2018). Hot news mining and public opinion guidance analysis based on sentiment computing in network social media. Personal and Ubiquitous Computing, 23(3-4), 373-381.

[8] Alcala-Fdez, J. , Bonarini, A. , Flugy-Pape, N. , \& Herrera, F. . (2010). Analysis of the effectiveness of the genetic algorithms based on extraction of association rules. Fundamenta Informaticae, 98(1), $1-14$. 